\title{
POLÍTICA PÚBLICA DE ASSISTÊNCIA SOCIAL: ESTRATÉGIA DE DESENVOLVIMENTO E COMBATE À POBREZA
}

\author{
PUBLIC POLICY SOCIAL ASSISTANCE: STRATEGY DEVELOPMENT \\ AND COMBATING POVERTY
}

\author{
Nilsen Aparecida Vieira Marcondes ${ }^{1}$ \\ Elisa Maria Andrade Brisola ${ }^{2}$
}

\begin{abstract}
RESUMO
Considera-se muito pertinente a reflexão acerca da condição de pobreza e estratégias de desenvolvimento. Neste aspecto, a Política Pública de Assistência Social apresenta sua contribuição na efetivação da garantia dos direitos de cidadania considerados como estratégia de desenvolvimento e combate à pobreza. Este artigo se configura como qualitativo, exploratório e bibliográfico. Os resultados deste estudo teórico apontam que o Estado, enquanto poder público, tem um papel fundamental no processo de proteção social mediante ações direcionadas ao investimento na área social e ao enfrentamento das situações decorrentes do processo de produção e reprodução do sistema capitalista.
\end{abstract}

Palavras-chave: Política Pública. Assistência Social. Pobreza. Desenvolvimento.

\begin{abstract}
It is considered very pertinent reflection on the condition of poverty and development strategies. In this aspect, Public Policy Social Welfare presents their contributions in the effective guarantee of citizenship rights considered as a strategy for development and poverty alleviation. This article is configured as qualitative, exploratory and literature. The results of this theoretical study show that the State, as power authority, has a fundamental role in the process of social protection through actions directed to invest in social and coping with situations arising from the process of production and reproduction of the capitalist system.
\end{abstract}

Keywords: Public Policy. Social Assistance. Poverty. Development.

\footnotetext{
${ }^{1}$ Mestrado em Desenvolvimento Humano: Formação , Políticas e Práticas Sociais, pela Universidade de Taubaté (UNITAU). Assistente Social na Prefeitura Municipal de São José dos Campos. Email: nilsenmarcondes@gmail.com.

${ }^{2}$ Doutorado em Serviço Social pela Pontifícia Universidade Católica de São Paulo (1996 e 2003 respectivamente). Docente na Universidade de Taubaté. Email: elisabrisola@uol.com.br.
} 


\section{Introdução}

A realização de uma retrospectiva sócio-histórica da assistência social se apresenta como oportuna na medida em que contribui para situar, no cenário brasileiro, as estratégias utilizadas pelo poder público no combate à pobreza visando ao desenvolvimento da nação.

Em seus primórdios, a assistência social não se caracteriza como direito. Entretanto, no desenrolar dos fatos históricos, verifica-se a insurgência de um processo gradativo de rompimento com este aprisionamento, ou seja, esta concepção adjutória gestada no interior de uma ideologia dominante defensora de ações residuais e focadas vai sendo paulatinamente substituída pela concepção de política pública. É a partir da Constituição Federal de 1988 que assistência social passa a compor a Seguridade Social, junto à saúde e à previdência social, portanto, reconhecida como política no campo dos direitos sociais, como uma política de proteção social (AFONSO, 2006; PAIVA, 2006).

Sabe-se que o direito somente se torna direito quando é regulamentado porque isso permite que seja conquistado e reclamado. Primeiramente, é necessário ter consciência de que se tem direito e para isso é preciso que ele esteja escrito em algum lugar, que ele seja regulamentado e tornado público, para que, num segundo momento, se possa tornar este direito reclamável. E isso é muito importante porque a assistência social historicamente foi vista como caridade, filantropia, favor que o Estado ou alguma organização social prestava aos desvalidos em condição de pobreza.

Isto posto, reforça-se que a pesquisa teórica aqui empreendida se configura como qualitativa quanto à forma de abordagem da temática, como exploratória do ponto de vista de seus objetivos e, com relação aos procedimentos técnicos, como bibliográfica.

Este texto se apresenta dividido em três partes: introdução, desenvolvimento e considerações finais. As reflexões se situam em torno de conceituações de alguns termos de uso corriqueiro na ambiência da política pública da assistência social, tais como: caridade, filantropia, vulnerabilidade social, organização social, proteção social básica, proteção social especial de média ou alta complexidade, Centro de
Referência de Assistência Social, Centro de Referência Especializado de Assistência Social, rede de proteção social, matricialidade sociofamiliar, descentralização político-administrativa e territorialização.

$\mathrm{Na}$ sequência, e paralelamente às definições conceituações, são apresentadas algumas análises histórico-críticas dos instrumentos democráticos que respaldam as estratégias de desenvolvimento e combate à pobreza, como a Lei Orgânica da Assistência Social, a Política Nacional de Assistência Social e o Sistema Único da Assistência Social. Por último, encerram-se as discussões com as considerações finais.

\section{Desenvolvimento}

Ao se tratar do tema pobreza e desenvolvimento, urge a necessidade de se definir alguns conceitos relacionados, como, por exemplo, a diferenciação entre as categorias caridade e filantropia. Entende-se por caridade uma ação motivada pelo sentimento de compaixão pelo próximo ou em defesa de alguma causa em especial, podendo partir tanto do plano individual quanto do coletivo, não sendo necessariamente importante a presença de recursos financeiros para sua execução. Por exemplo, visitar doentes em hospitais, atuar como voluntário em alguma situação ou causa, enfim, praticar o bem sem a utilização de dinheiro também é uma das possibilidades para quem procura fazer ações pautadas na caridade. Filantropia, por sua vez, consiste numa ação planejada socialmente, sendo-lhe imanente algum interesse anterior e a necessidade de recursos financeiros para a efetivação das ações que se propõe a executar. Geralmente, ações filantrópicas estão vinculadas a projetos de desenvolvimento ecologicamente sustentável ou desenvolvimento social, cultural ou econômico, entre outros (PEREIRA, 2004).

Quanto à conceituação de organização social, Simões $(2010$, p. 449) traz a seguinte definição: “A organização social é uma pessoa jurídica de direito privado e sem fins lucrativos, criada por particulares, sob a forma societária, que se habilita, perante a administração pública, a obter sua qualificação, por meio da qual é declarada como entidade de interesse social e utilidade pública" (grifo do autor).

Essas organizações foram criadas pela Lei $n^{\circ}$ 9.637, em 15 de maio de 1998, e direcionam suas ações nas áreas de assistência social, saúde, educação, 
pesquisa científica, desenvolvimento tecnológico, proteção e preservação do meio ambiente e cultura (BRASIL, 1998).

As organizações sociais citadas neste artigo se referem às organizações de assistência social que, de forma continuada, permanente e planejada, prestam serviços ou executam programas ou projetos dirigidos aos indivíduos e famílias demandatários da política de assistência social.

Essas organizações apresentam três concepções diferenciadas conforme o amparo jurídico-legal que lhes é destinado. São de atendimento as que repassam benefícios de prestação social básica ou especial às famílias e indivíduos em situações de vulnerabilidade ou risco social e pessoal. São de $a s-$ sessoramento aquelas voltadas essencialmente para o fortalecimento dos movimentos sociais e das organizações de usuários, formação e capacitação de lideranças. São de defesa e garantia de direitos aquelas que focam suas ações prioritariamente na defesa e materialização dos direitos socioassistenciais, construção de novos direitos, promoção da cidadania, enfrentamento das desigualdades sociais e articulação com órgãos públicos de defesa de direitos (BRASIL, 2011, grifos nossos).

A aprovação da Lei Orgânica da Assistência Social (LOAS) em 7 de dezembro de 1993 sob o no 8742 representou um avanço e um marco na área da assistência social. Esta lei defende que o Estado é o primeiro responsável pela condução da Política de Seguridade Social e define que sua gestão seja efetivada por meio de um sistema descentralizado e participativo. Além disso, possui princípios fundamentais como: a preeminência do atendimento às necessidades sociais sobre as requisições de rentabilidade econômica; a universalização dos direitos sociais; a consideração à dignidade da pessoa, à sua autonomia e ao seu direito a benefícios e serviços de qualidade; a igualdade de direitos no acesso ao atendimento livre de discriminação de qualquer ordem (BRASIL, 1993).

De acordo com Silveira (2009), a forma como se efetivou a implementação da LOAS no cenário brasileiro demarca alterações institucionais e políticas significativas para delimitação do direito à assistência social no cenário do sistema protetivo brasileiro. $\mathrm{Na}$ LOAS, o princípio da descentralização políticoadministrativa, materializado na consolidação dos fóruns, conselhos de direitos, instâncias deliberativas de recursos públicos e organização da política da assistência nas três esferas de governo, ganha força com a instituição de um sistema unificado e continuado.

Ao se tratar da Política Nacional de Assistência Social (PNAS), ressalta-se que sua aprovação por parte do Conselho Nacional de Assistência Social (CNAS) ocorreu em 15 de outubro de 2004, através da resolução $\mathrm{n}^{\circ} 145$, publicada no Diário Oficial da União em 28 de outubro de 2004. Tal Política se configurou como resultado de uma ampla mobilização por parte dos setores organizados, dos movimentos sociais e dos trabalhadores, dentre outros.

O foco da PNAS é a proteção social entendida como forma institucionalizada que as sociedades criam para, primeiro, proteger uma parte ou o conjunto total de seus membros de doenças, infortúnios, privações, etc., e, segundo, para promover o acesso aos bens materiais e culturais, permitindo que toda vida social possa sobreviver e se integrar, ou seja, caminhar sempre mais rumo ao desenvolvimento. Isso porque parte da população, principalmente a que vive em condição de pobreza, não tem acesso à qualidade de vida, tanto no que diz respeito aos bens materiais quanto aos bens culturais e saberes (BRASIL, 2004).

A PNAS afirma que a proteção social deve garantir: segurança de sobrevivência, com acesso ao rendimento e à autonomia; segurança de acolhida; segurança de convívio ou vivência familiar. $\mathrm{O}$ avanço desta política está no fato de entender e reconhecer as diferenças e a diversidade social em todo o território nacional, pensando numa política de diferentes lugares, para diversos locais, seja em uma cidade de cinco mil habitantes ou em uma metrópole de dez milhões de habitantes. Verifica-se uma saída da esfera da caridade, do clientelismo e da benemerência para a entrada na esfera do direito (BRASIL, 2004). Portanto, constituem seguranças afiançadas pela assistência social: a acolhida, o convívio familiar e comunitário, a renda, o desenvolvimento da autonomia e a sobrevivência a riscos circunstanciais (BRASIL, 2012).

A PNAS, considerada como política pública, dever do Estado e direito de cidadania, busca direcionar os instrumentos normativos que a respalda no enfrentamento dos riscos sociais, além de consubstanciar sua atuação na prevenção destes 
riscos. Dessa forma, tal política reafirma os preceitos da Constituição Federal e da LOAS, estabelecendo uma harmonia entre estas diretrizes e princípios, culminando com a implantação do Sistema Único de Assistência Social (SUAS).

O SUAS começou a ser construído a partir da promulgação da LOAS, em 1993, e chegou ao estabelecimento de sua base com a aprovação da PNAS, no final de 2004. Esse sistema descentralizado e participativo preconiza que o Governo Federal deve rever seu papel, bem como aumentar a autonomia dos municípios para atuar na política de assistência social, possibilitando que os estados possam oferecer maior suporte aos municípios sempre que precisarem, pois afirma defender a importância da dimensão territorial e solidificação dos princípios contidos na LOAS (BEHRING; BOSCHETTI, 2010).

O SUAS representa a principal deliberação da IV Conferência Nacional de Assistência Social convocada por meio da Portaria $\mathrm{n}^{\circ} 262$, de 12 de agosto de 2003, e tendo como ponto de partida sua implantação em julho de 2005, com a aprovação da Norma Operacional Básica (NOB). O projeto de lei que o institui (PLC 189/2010) foi aprovado no plenário do Senado no dia 8 de junho de 2011. Tal projeto, de autoria do Executivo, e que passou por várias comissões e pelos plenários da Câmara e do Senado, depois seguiu para sanção da presidente Dilma Rousseff.

O SUAS foi consequência de debates realizados pela sociedade brasileira por quase duas décadas, sociedade esta desejosa de colocar em prática os princípios da Constituição de 1988, que incorpora a assistência social à Seguridade Social, com a saúde e a previdência social. Em conformidade com as normatizações da Constituição Federal e da LOAS, o SUAS se apresenta como um sistema público não contributivo, descentralizado e participativo, cuja finalidade precípua é a gestão da matéria específica da assistência social no campo da proteção social brasileira (BRASIL, 2005).

Segundo Afonso (2006) e Paiva (2006), a construção desse Sistema se alicerçou no esforço de pôr fim à forma de prestação de serviço na área da assistência até então implantada no Brasil, forma tradicional recorrente mesmo depois da aprovação da LOAS. Assim, muitas ações e iniciativas de atendimento à população em situação de vulnerabilidade social deixam o campo do voluntariado e passam a ser executadas sob a estrutura de uma política pública de Estado, deixando de possuir a configuração de favor, de benefício assistencial para direito do cidadão.

Entende-se por vulnerabilidade social o estado em que uma pessoa, grupos sociais ou famílias se encontram quando vivem numa situação de pobreza, privação decorrente da ausência de renda, acesso insuficiente ou inexistente aos serviços públicos e/ ou fragilização de vínculos afetivos relacionais e de pertencimento social como, por exemplo, discriminações de qualquer ordem (BRASIL, 2005).

O SUAS integrou serviços, programas e benefícios e, de certa forma, trouxe avanços para a assistência social brasileira. Nesse novo contexto, os governos municipais, estaduais e federal são considerados órgãos gestores da política de assistência social enquanto responsáveis pela formulação e execução dessa política no âmbito do município, estado ou união.

Para Iamamoto (2011), esta primazia da responsabilidade estatal na oferta dos serviços, programas, projetos e benefícios socioassistenciais reforça que o Estado tem um papel fundamental neste processo de proteção social mediante ações direcionadas ao investimento na área social e ao enfrentamento das situações decorrentes do processo de produção e reprodução do sistema capitalista.

O sistema capitalista, ao subjugar toda a sociedade, busca seu contínuo crescimento ao mesmo tempo em que acirra os processos de desigualdades, pois se apresenta insensível em face das necessidades e direitos da grande maioria da população. Santos Neto (2011), ao acrescentar elementos a essa reflexão, destaca categoricamente que a gênese e o desenvolvimento do capitalismo apontam sua expansão sem fronteiras em diferentes regiões do planeta, e como ressonância de seus ecos, arruínam antigos sistemas de produção e remotas economias primitivas. A perspectiva de desenvolvimento imposta às nações por parte do sistema capitalista traz consigo princípios norteadores sustentados por uma ideologia baseada na exploração máxima da força de trabalho. Portanto, segundo Borchardt (1982), há de se justificar a relação conflituosa entre capitalista e assalariado que remonta à origem do capital como algo imanente a este sistema.

O SUAS fortalece a ideia de que só o Estado, enquanto conjunto de instituições que controlam e 
administram um país, é capaz de garantir os direitos e o acesso universal aos que necessitam assistência social, preconizando as diferentes formas de proteção social devidas por este, como a proteção social básica e a proteção social especial de média e alta complexidade. Assim, a assistência social passa a ser organizada de acordo com as necessidades sociais específicas, que são heterogêneas (AFONSO, 2006).

A proteção social pode ser ofertada de forma direta, pelo poder público, ou de forma indireta, por organizações sociais vinculadas ao SUAS. A efetivação dessa proteção no contexto da assistência social, em conformidade com as normatizações estabelecidas pela PNAS e pelo SUAS, materializa-se na garantia de seguranças sociais devidas aos cidadãos, visando à prevenção e diminuição de riscos, da violação de direitos humanos e de vulnerabilidades sociais (SILVEIRA, 2009).

A Resolução ${ }^{\circ} 109$, de 11 de Novembro de 2009, que trata da Tipificação Nacional de Serviços Socioassistenciais, traz definições do que se compreende por proteção social básica, proteção social especial de média e alta complexidade. Entende-se por proteção social básica o trabalho social desenvolvido com famílias e que possua caráter continuado, tendo por finalidade tornar forte a função protetiva dessas famílias; antecipar-se a possível ruptura dos seus vínculos, contribuindo para sua prevenção; impulsionar o acesso e o usufruto dos direitos; favorecer a melhoria da qualidade de vida (BRASIL, 2009).

Consoante à mesma Resolução, a proteção social especial de média complexidade se configura como prestação de serviços de apoio, orientação e acompanhamento a famílias em que um ou mais membros se encontrem em situação de ameaça ou violação de direitos, objetivando promover direitos, preservar e fortalecer os vínculos familiares, comunitários e sociais e fortalecer a função protetiva das famílias em face das diversas realidades que as vulnerabilizam e/ou as submetem a situações de risco pessoal e social (BRASIL, 2009).

Por proteção social de alta complexidade, entende-se o acolhimento em distintos tipos de unidades de atendimento, destinadas a famílias e/ou indivíduos com vínculos familiares rompidos ou fragilizados, de modo que possa ser garantida a proteção integral, priorizando o atendimento personalizado e em pequenos grupos (BRASIL, 2009).
O SUAS reforça ainda a importância de se atuar de maneira preventiva, protetiva e proativa, considerando relevante a emissão de respostas às necessidades humanas integralmente, para além do enfoque a questões emergenciais, centradas unicamente nas realidades que se configuram como de risco social (BRASIL, 2012). Nas palavras de Colin (2012, p. 5): "O SUAS defende a centralidade e responsabilidade do Estado no atendimento e acompanhamento das famílias, de modo proativo, protetivo, preventivo e territorializado, assegurando o acesso a direitos e a melhoria da qualidade de vida".

Atuar de forma preventiva significa desenvolver ações que busquem prevenir

situações que possam interferir no exercício dos direitos de cidadania. Falar em prevenção, no âmbito do SUAS, indica a necessidade de focar em ações antecipadas que estejam respaldadas pelo conhecimento do território, dos fenômenos, de suas características específicas, como aspectos culturais, sociais e econômicos, e das famílias e suas histórias de vida. O caráter preventivo demanda, portanto, intervenções voltadas às tentativas de impedimento de ocorrência ou de agravamento de situações de vulnerabilidade e risco social que podem dificultar o acesso dos sujeitos individuais ou coletivos aos seus direitos (BRASIL, 2012).

A atuação protetiva se traduz na centralização de esforços interventivos que visam amparar, apoiar, auxiliar, resguardar ou defender o acesso das famílias e seus membros aos seus direitos. Estes objetivos das intervenções de caráter protetivo devem, portanto, solidificar esforços na direção da defesa, da garantia e da promoção dos direitos das famílias. Quanto à atuação proativa, sua definição parte da premissa de que é necessário imprimir um movimento na direção do reconhecimento, responsabilização e intervenção em situações que estas se apresentam como potencial problema que pode vir a impedir o acesso do indivíduo ou da família aos seus direitos, mas que ainda não se configuram como tal (BRASIL, 2012).

A proatividade é o inverso da reatividade, considerada como capacidade de reação aos estímulos externos. Ser proativo significa tomar a iniciativa, promovendo intervenções antecipadas ou imediatas frente a situações de vulnerabilidade ou risco social, que possa vir a afetar a realidade das famílias ou dos territórios. Significa ainda não 
esperar que a demanda chegue à porta das unidades de atendimento. A intervenção proativa tem por objetivo intervir nas circunstâncias que se apresentam como bases fundantes das situações de vulnerabilidade e risco social. A proatividade possibilita que se criem instrumentos capazes de prever ocorrências futuras, buscando o aperfeiçoamento contínuo da ação, de forma que o acesso das famílias aos seus direitos seja efetivo e mais ágil. A proatividade é essencial na concretização da intervenção preventiva e protetiva no âmbito da PNAS (BRASIL, 2012).

No processo de implantação do SUAS, destaca-se a atuação dos profissionais nos serviços socioassistenciais ofertados, particularmente nas unidades públicas estatais. Esses equipamentos estatais que atribuem visibilidade ao SUAS têm como perspectiva contribuir para a democratização dos direitos socioassistenciais, de forma a produzir impactos na vida dos demandatários dos serviços. Eles representam as portas de entrada para o SUAS e são nominados como Centro de Referência de Assistência Social (CRAS), que atua na perspectiva da proteção social básica, e Centro de Referência Especializado de Assistência Social (CREAS), que direciona suas ações na dimensão da proteção social especial (SILVEIRA, 2009).

De acordo com a Lei Federal 12.435, de 6 de Julho de 2011, CRAS é uma unidade pública municipal, que possui sua base no território, devendo, preferencialmente, estar localizada em espaços geográficos que possuam elevados índices de vulnerabilidade e risco social. Na sua área de abrangência, as diretrizes das intervenções realizadas pelo CRAS, pautam-se na identificação das situações de vulnerabilidade e risco social, na articulação da rede prestadora de serviços socioassistenciais, na execução de serviços e na operacionalização de programas e projetos socioassistenciais de proteção social básica direcionados às famílias, grupos e indivíduos (BRASIL, 2011).

Nesses equipamentos estatais são prestadas orientações, a realização de atendimentos socioassistenciais, o desenvolvimento de ações com cunho político-pedagógico e a execução de encaminhamentos para a rede de proteção social que compõem os demais prestadores de serviços governamentais e não governamentais.

A definição de rede de proteção social, comumente denominada rede socioassistencial, está imbricada à dimensão capilar existente no fluxo de atendimento previsto em seu interior. Essa oferta capilar possibilita a universalização dos acessos por meio de uma sistemática e contínua prestação de serviços socioassistenciais de cunho políticopedagógico e preventivo de violação de direitos, tendo em conta as necessidades sociais e expectativas dos demandatários da assistência e a mediação com programas, projetos, benefícios e outras políticas públicas (SILVEIRA, 2009).

Para Colin (2012), a característica capilar que a proteção social básica possui, aliada a sua capacidade de referenciamento somada ao fato de o CRAS estar localizado em lugares de vulnerabilidade social ou nas proximidades desses locais, legitimou e tornou essa unidade pública estatal uma referência para aqueles que residem na sua área de abrangência.

A mesma Lei Federal 12.435, de 6 de Julho de 2011, que conceitua o CRAS, define que o CREAS também se configura como uma unidade pública, mas sua abrangência e gestão pode ser municipal, estadual ou regional. O CREAS se destina à prestação de serviços a indivíduos e famílias que estão envolvidos em situações de risco pessoal ou social, em decorrência da violação de seus direitos ou de realidades que exigem intervenções especializadas da proteção social especial (BRASIL, 2011).

Assim como o CRAS, o CREAS também realiza intermediação com diferentes políticas públicas, articulando e coordenando ações, além de ofertar serviços e benefícios de assistência social e operacionalizar programas e projetos (BRASIL, 2011). De acordo com Silveira (2009, p. 349): "No CREAS, tem-se a prestação de serviços especializados e continuados a indivíduos e famílias com seus direitos violados, promovendo a integração de esforços, recursos e meios para enfrentar a dispersão e a desproteção social na prestação dos serviços".

A intervenção nesses equipamentos se volta à tentativa de recompor os direitos violados. A peculiaridade dos problemas emergentes dessa violação faz com que seja necessário o favorecimento da proteção tanto às pessoas quanto às famílias. Os princípios contidos no SUAS, destinados a orientar os profissionais que atuam nos CREAS, contribuem para a compreensão de que nessa prestação de serviço é preciso buscar o desenvolvimento de 
ações que considerem as situações de violência e as contingências individuais e coletivas, de forma a resgatar ou favorecer a ampliação das capacidades para o enfrentamento dessas situações, pela reconstrução de projetos de vida e restabelecimento dos vínculos afetivos (SILVEIRA, 2009).

Os fundamentos da construção e consolidação do SUAS se pautam em três eixos estruturantes: a matricialidade sociofamiliar, a descentralização político-administrativa e a territorialização (BRASIL, 2012). Essas categorias que compõem o universo temático da política de assistência social na atualidade não obstante contribuírem para a materialização do SUAS e devem ser compreendidas também para além do horizonte da simples aceitação de que representam somente avanços. $\mathrm{O}$ ato de posicionar referidos dilemas objetiva impedir que se sucumba ao aprisionamento ideológico da estrutura estatal, a qual recebe diretas influências do capitalismo.

As estruturas de poder político e econômico no Brasil tendem a referenciar essas três categorias presentes no âmbito do provimento das necessidades sociais, como aprimoramento da esfera governamental na direção da consolidação da PNAS, de forma inovadora e transformadora. Entretanto, um mecanismo estratégico não evidenciado dissimula as complexas contradições presentes na demarcação da natureza de cada um desses eixos estruturantes.

Quanto à matricialidade sociofamiliar, por exemplo, o SUAS defende que a família deve ocupar posição de destaque, reforçando que anteriormente o foco do trabalho se voltava a segmentos da população como criança e adolescente, idosos, pessoas com deficiência, mulheres, indígenas, etc. No atual contexto, argumenta-se acentuadamente a característica pretensamente original do trabalho com famílias. Entretanto, a história do Serviço Social demonstra que a intervenção profissional sempre foi pautada no trabalho com famílias. O que houve anteriormente à implantação do SUAS foi o Estado dissimular a ausência de investimentos públicos em políticas de atendimento às famílias, imprimindo um mistificado caráter segmentado à ação dos trabalhadores envolvidos com a assistência social. Não obstante, isso não inviabilizou as recorrentes práticas voltadas à família. Portanto, ressalta-se e reforça-se a importância do trabalho com famílias, mas se insiste no fato de que isso não se configura como novidade, conforme preconiza o SUAS (AFONSO, 2006; LOPES, 2006; PAIVA, 2006).

Outra realidade que merece destaque referente à defesa da matricialidade sociofamiliar por parte do SUAS diz respeito ao fato de que, embora atualmente seja evidenciada por meio da fala oficial a importância da atuação junto às famílias, o investimento dos recursos públicos ainda permanece voltado aos segmentos da população. Sabe-se que uma das realidades que contribuem para reforçar a densidade político-emancipatória das políticas sociais se assenta, por exemplo, nos programas de transferência de renda. Esses programas são responsáveis por atribuir alterações efetivas na vida da população demandatária da assistência. Entretanto, todos eles se pautam num repasse financeiro baseado em segmentos tais como criança e adolescente, idoso, pessoa portadora de deficiência, gestante e nutriz, dentre outros. E ainda, existe uma cobrança por parte do Estado para que esses segmentos cumpram determinadas funções e assumam certas condutas, sendo a família responsabilizada e chamada somente nas ocasiões em que se faz necessário mediar conflitos que se manifestam durante o convívio entre seus membros (SILVA E SILVA et al., 2012).

Afonso (2006), Lopes (2006) e Paiva (2006), consideram, portanto, em consonância com o que é preconizado no SUAS, a importância do trabalho com famílias. Esses autores defendem que as famílias devem contar com uma rede de proteção social, não somente pelo fato de elas serem consideradas pelo SUAS como elo social básico na reconstrução de vínculos pessoais e sociais que foram interrompidos ou fragilizados, mas também porque representam um grupo social com direito a serviços de apoio em todas as suas necessidades.

Segundo a publicação do Conselho Federal de Serviço Social (CFESS) intitulada "Atuação do Assistente Social no CRAS", o trabalho com famílias é realizado mediante desenvolvimento de ações individuais aos seus membros, ao grupo familiar, a grupos de famílias e à coletividade. Tais ações, compreendidas como apoio, orientação e encaminhamentos, se direcionam nas dimensões relacionais (vínculos, autoridade, afeto, valores) na prevenção de riscos e na promoção de direitos (CONSELHO FEDERAL DE SERVIÇO SOCIAL, 2009). 
O fortalecimento dos vínculos familiares, comunitários e sociais traz benefícios para as famílias que se encontram em situação de vulnerabilidade, na medida em que possibilita o aumento da expectativa de vida e o alcance das oportunidades oferecidas. Portanto, trabalhar com famílias requer garantir espaços de convívio, prestação de informações, garantia de defesa da autonomia e emancipação social em uma perspectiva crítica, bem como favorecer o acesso aos direitos socioassistenciais, contribuindo para a consolidação da gestão intersetorial no território referenciado e o desenvolvimento da capacidade protetiva da família e de seus membros (COLIN, 2012).

No documento "Orientações Técnicas sobre o Programa de Proteção e Atendimento Integral à Família" (PAIF), a oferta do serviço de convivência e fortalecimento de vínculos é primordial para a proteção daqueles que se encontram em situação de vulnerabilidade, sendo que tais serviços podem ser desenvolvidos tanto no interior do CRAS como em outras unidades públicas, ou ainda em organizações sociais (BRASIL, 2012).

No que se refere à descentralização político-administrativa, verifica-se que não obstante sua previsão no plano legal datar desde a Constituição Federal de 1988, sendo reforçada na LOAS em seus artigos $6^{\circ}, 8^{\circ}$ e $11^{\circ}$, sabe-se que isso se configura como processo gradativo, pois avanços consistentes nesse sentido demandam mobilização contínua dos setores organizados da sociedade. De acordo com Iamamoto (2011), isso se explica pelo fato de os antecedentes históricos de centralização, presentes no Brasil desde o período colonial, deixarem marcas profundas na cultura, influenciando a concepção da assistência social bem como sua forma de gestão. Portanto, a participação na vida política nacional, estadual e municipal se constitui como meta contínua a ser alcançada na direção do avanço do fortalecimento democrático.

\section{A PNAS coloca que:}

No campo da assistência social, o artigo $6^{\circ}$, da LOAS, dispõe que as ações na área são organizadas em sistema descentralizado e participativo, constituído pelas entidades e organizações de assistência social, articulando meios, esforços e recursos, e por um conjunto de instâncias deliberativas, compostas pelos diversos setores envolvidos na área.
O artigo $8^{\circ}$ estabelece que a União, os Estados, o Distrito Federal e os Municípios, observados os princípios e diretrizes estabelecidas nesta lei, fixarão suas respectivas políticas de assistência social. $\mathrm{O}$ artigo $11^{\circ}$ da LOAS coloca, ainda, que as ações das três esferas de governo na área da assistência social realizam-se de forma articulada, cabendo a coordenação e as normas gerais à esfera Federal e a coordenação e execução dos programas, em suas respectivas esferas, aos Estados, ao Distrito Federal e aos Municípios (BRASIL, 2004, p. 43).

Para a consolidação do SUAS, está normatizada a previsão de compartilhamento de responsabilidades em todas as esferas de gestão. $\mathrm{O}$ respeito às especificidades regionais e locais requer o efetivo desempenho desse papel. O cumprimento da primazia da responsabilidade do Estado na condução das ações que dizem respeito à assistência social reitera o imperativo de que a prestação dos serviços socioassistenciais deve ser ofertada pelo Estado de forma descentralizada.

No que concerne à sistematização e definição do SUAS, a percepção de Sposati (2006, p. 111112), assentada na afirmação que se segue, contribui para a ampliação da compreensão conceitual desse Sistema:

O SUAS não é um programa federal, isto é uma nova linha de financiamento federal para alguma atividade ou ação de assistência social a ser desenvolvida pelos governos estaduais e municipais diretamente, ou através de organizações sociais. $\mathrm{O}$ SUAS é uma racionalidade política que inscreve o campo de gestão da assistência social, uma das formas de proteção não contributiva, como responsabilidade do Estado a ser exercida pelos três entes federativos que compõem o poder público brasileiro. Nesse sentido, é uma forma pactuada que reflete o processo de gestão da assistência social, antes de iniciativa isolada de cada ente federativo, a uma compreensão política unificada dos três entes federativos quanto ao seu conteúdo (serviços e benefícios) que competem a um órgão público afiançar ao cidadão.

A política de assistência social procura manter uma postura fidedigna aos princípios norteadores da universalidade e da gratuidade de atendimento. "Isso significa que o serviço deve ser organizado de forma a atender indiscriminadamente todas as famílias do território de abrangência do CRAS, sem exigir 
nenhuma forma de pagamento ou contrapartida" (BRASIL, 2012, p. 20). Compreende-se, portanto, a partir dessa ótica que cabe exclusivamente à esfera estatal, a implementação e oferta de serviços socioassistenciais, bem como a responsabilidade pelo acompanhamento das famílias. O respeito à autonomia dos municípios, defendido na descentralização político-administrativa, implica na defesa de que a execução e gestão de ações não devem ser terceirizadas.

O arcabouço textual da PNAS explicita que:

A política de assistência social tem sua expressão em cada nível da Federação na condição de comando único, na efetiva implantação e funcionamento de um Conselho de composição paritária entre sociedade civil e governo, do Fundo, que centraliza os recursos na área, controlado pelo órgão gestor e fiscalizado pelo Conselho, do Plano de Assistência Social que expressa a política e suas inter-relações com as demais políticas setoriais e ainda com a rede socioassistencial. Portanto, Conselho, Plano e Fundo são os elementos fundamentais de gestão da Política Pública de Assistência Social. Dessa forma, cabe a cada esfera de governo, em seu âmbito de atuação, respeitando os princípios e diretrizes estabelecidos na Política Nacional de Assistência Social, coordenar, formular e cofinanciar, além de monitorar, avaliar, capacitar e sistematizar as informações (BRASIL, 2004, p. 43).

Quanto à territorialização, é relevante considerar que sua adoção enquanto mecanismo de identificação das necessidades e estudo das respostas socioinstitucionais leva à compreensão e consideração das vulnerabilidades e riscos pessoais numa dimensão territorial, o que representa um aspecto positivo do SUAS. A territorialização se apresenta como possibilidade de reconhecimento das condições favoráveis com a finalidade de alcançar objetivos específicos, ou seja, permite que a demanda pelos serviços da área da assistência social, circunscrita no âmbito do território, possa incidir diretamente na rede socioassistencial, a qual procura responder aos limites de suas possibilidades técnicas e de gestão (SILVEIRA, 2009).

Referenciar limites técnicos e de gestão ao enfatizar a articulação de ações desenvolvidas na rede socioassistencial é importante, e isso porque se tem clareza de que um dos mais importantes desafios que se colocam às políticas públicas é o da superação da fragmentação que as caracteriza externa e internamente. Essa superação permite que se alcance uma compreensão integrada dos dilemas sociais e de suas resolutividades, o que implica, por sua vez, em uma mudança na maneira como se estabelece a comunicação e a ação entre os distintos segmentos da unidade governamental e dos seus interesses. A compreensão integrada dos dilemas sociais e da intervenção articulada em rede emana como uma alternativa que permite partir para o enfrentamento das vulnerabilidades e riscos sociais que recaem sobre uma população em determinado território, uma vez que a conjuntura social demanda intervenções que não se exaurem no âmbito de uma política social específica e única (BRASIL, 2012).

$O$ respeito à territorialização expressa por sua vez o respeito à heterogeneidade do território brasileiro. A especificidade local influencia na consolidação das redes socioassistencial e intersetorial, as quais podem apresentar distintas expressões. Diante disso, não se pode adotar um modelo único de rede de proteção social que possa ter sua efetividade padronizada a todos os municípios. É necessário ter presente também que as redes estão sujeitas a contínuas mudanças, as quais são inerentes às demandas que se apresentam e que clamam por respostas (BRASIL, 2012).

A regulamentação e o estabelecimento das bases do SUAS, bem como a forma de proceder a uma nova organização da rede socioassistencial, perpassam necessariamente pelo investimento em inovações institucionais, técnicas e tecnológicas, sendo que o desdobramento dessas inovações aponta para diferentes direções, sendo todas imprescindíveis para o desenvolvimento do SUAS. Dentre essas inovações, destacam-se quatro necessidades: aperfeiçoar e desenvolver o aparato estatal municipal e estadual, responsáveis pela implantação e implementação de ações para a área da assistência social; assegurar a efetividade e a ampliação do financiamento nas instâncias municipal, estadual e federal, de forma a atender as demandas por serviços socioassistenciais advindas das três esferas poder; fazer uso de ferramentas democráticas de gestão; investir no setor público de modo a torná-lo mais eficiente na prestação dos serviços e enfrentamento das desigualdades (SILVEIRA, 2009). 
No SUAS, o território é compreendido como um município de pequeno porte ou um bairro ou uma vila de um município de médio ou grande porte, de uma cidade ou mesmo de uma metrópole. Portanto, o oferecimento de programas, projetos e serviços socioassistenciais com base em territórios possibilita a proximidade adequada entre a oferta e os usuários, bem como a gestão dos serviços, dos benefícios e da renda. Assim, uma quantidade maior de pessoas pode acessar o atendimento (AFONSO, 2006).

De acordo com Carvalho (2006), na perspectiva dos eixos descentralização político-administrativa e territorialização, um dilema que se apresenta como digno de reflexão se refere ao ocultamento por parte do Estado da limitada autonomia dos municípios. Essa realidade que se evidencia no âmbito local faz com que os municípios reduzam suas respostas em direção da efetivação de todas as possibilidades de avanço na área da assistência social.

$\mathrm{Na}$ contramarcha desses dois eixos estruturantes do SUAS, verifica-se na atualidade que os municípios não conseguem implantar programas sociais de forma autônoma e de acordo com sua realidade local, porque os mesmos envolvem investimentos financeiros, os quais nem sempre estão disponibilizados nos municípios na quantidade necessária, devendo, portanto, recorrer a outras esferas de poder, no caso, financiamento por parte do governo federal. Porém, os programas nos moldes determinados pelo governo federal, os quais, portanto, são passíveis de financiamento, muitas vezes não condizem com a realidade dos municípios. Nesse impasse, o município acaba tendo de se adequar às exigências federais, caso contrário, não poderá contar com apoio financeiro para desenvolvimento de seus programas (CARVALHO, 2006).

Apesar de o SUAS defender a descentralização político-administrativa e a territorialização, a materialização da articulação desses eixos no âmbito municipal tem sofrido pressão por parte do Estado, que prioriza investimento em programas de interesses federais. Com isso, alguns municípios que possuem programas considerados de referência em seus respectivos territórios correm o risco de perder as possibilidades financeiras para sua sustentação caso não sejam considerados como prioridade de investimento federal. Medidas coercitivas como essas, as quais limitam a autonomia municipal, justificam as motivações que têm levado as gestões políticas municipais a correr atrás dos editais federais em busca de implantação e implementação de programas que contem com subvenções financeiras independentemente de suas realidades locais (CARVALHO, 2006).

Dificilmente uma gestão política municipal se manifestará contrária à adesão daquilo que é proposto nos editais federais, assumindo publicamente para a população que o município optou por não concorrer ao recebimento de investimentos financeiros, porque aquele determinado programa não condiz com a realidade local da assistência social. Carvalho (2006, p. 127) traduz bem essa realidade ao afirmar que "nossos pequenos municípios, em sua maioria, padecem da ausência de recursos próprios para dar conta de políticas locais de desenvolvimento e são absolutamente dependentes de transferências federais e estaduais."

Portanto, são dilemas como aqueles citados na categoria "matricialidade sociofamiliar" e estes elencados na "descentralização político-administrativa" e na "territorialização" que não podem ser desconsiderados quando se propõe realizar um debate em torno dos eixos estruturantes do SUAS.

\section{Considerações finais}

O desafio, por conseguinte, está em o SUAS materializar aquilo que se propõe a realizar quando preconiza a consolidação de seus três eixos estruturantes (AFONSO, 2006; CARVALHO, 2006; LOPES, 2006; PAIVA, 2006; SILVA E SILVA et al., 2012). Tal desafio também possui dimensões ampliadas, porque o histórico modelo político e econômico de sociedade erigido no Brasil, do ponto de vista dos direitos de acesso à riqueza socialmente produzida, revela estratégico movimento dual por parte da classe dominante. Os padrões estabelecidos para acesso aos bens, além de não favorecer a justiça, não favorecem a inserção de todos aqueles que necessitam adentrar no mercado de trabalho formal (PAIVA, 2006).

Por outro lado, e não obstante evidência de deletérios esquemas presentes no SUAS, isso não invalida a compreensão de que esse sistema também se apresenta como um importante avanço na defesa da assistência social enquanto política pública de direitos, conforme considerada na 
Norma Operacional Básica de 2005 (NOB/2005). Essa constatação é reforçada na NOB quando traz a seguinte conceituação: "a assistência social é considerada como política pública de direção universal e direito de cidadania, capaz de alargar a agenda dos direitos sociais a serem assegurados a todos os brasileiros, de acordo com suas necessidades e independente de sua renda, a partir de sua condição inerente de ser direito" (BRASIL, 2005, p. 6).

À luz das definições textuais da NOB/2005: "A PNAS deve se pautar em prover proteção à vida, reduzir danos, monitorar populações em risco e prevenir a incidência de agravos à vida face às situações de vulnerabilidade" (BRASIL, 2005, p. 6). Portanto, nessa perspectiva, pode-se falar em uma possibilidade de construção de uma cultura de cidadania, rompendo com a concepção neoliberal que nega a responsabilidade do Estado na proteção social.

Por fim, os diversos profissionais que atuam na política de assistência social estão envolvidos com a edificação do SUAS. São os trabalhadores sociais que atuam no CRAS, no CREAS e nas organizações sociais vinculadas ao SUAS que, por meio de suas respectivas ações, viabilizam a prestação dos serviços socioassistenciais, os quais se configuram como forma de alcance das seguranças protetivas defendidas pela PNAS. Por conseguinte, direcionar o exercício profissional cotidiano no CRAS e CREAS, no que diz respeito aos procedimentos, fluxos e estratégias profissionais, exige uma leitura teórico-política e crítica da conjuntura social, por meio da compreensão das realidades atuais que resultam em demandas, planejamento, execução e avaliação das intervenções (SILVEIRA, 2009).

\section{Referências}

AFONSO, L. Trabalho com famílias-PBF/PAIF. Brasília: [s.n.], 2006.

BEHRING, E. R.; BOSCHETtI, I. Política Social: fundamentos e história. 7. ed. São Paulo: Cortez, 2010.

BORCHARDT, J. Karl Marx O Capital. 7. ed. Rio de Janeiro: Editora Guanabara, 1982.

BRASIL. Presidência da Republica. Lei Federal 8.742, de 07 de dezembro de 1993. Dispõe sobre a Lei Orgânica da Assistência Social - LOAS, Brasília, DF, 1993.

Presidência da Republica. Lei Federal 9. 637, de 15 de maio de 1998. Brasília, DF, 1998. Disponível em: <http://
www.planalto.gov.br/ccivil_03/leis/L9637.htm>. Acesso em: 07 fev. 2012.

. Ministério do Desenvolvimento Social e Combate à Fome. Secretaria Nacional de Assistência Social. Política Nacional de Assistência Social. Brasília, DF, 2004.

. Ministério do Desenvolvimento Social e Combate à Fome.Secretaria Nacional de Assistência Social. Norma Operacional Básica do SUAS. Brasília, DF, 2005.

Diário Oficial da República Federativa do Brasil, 25 nov. 2009. Resolução $\mathbf{n}^{\mathbf{0}} \mathbf{1 0 9}$, de 11 de novembro de 2009. Dispõe sobre a Tipificação Nacional de Serviços Socioassistenciais, Brasília, DF, 2009.

Presidência da República. Lei Federal 12.435, de 06 de junho de 2011. Dispõe sobre a organização da Assistência Social,Brasília, DF, 2011. Disponível em: <www.planalto. gov.br/ccivil_03/Ato2011-2014/.../Lei/L12435.htm>. Acesso em: 07 fev. 2012.

. Ministério do Desenvolvimento Social e Combate à Fome. Secretaria Nacional de Assistência Social. Orientações Técnicas sobre o PAIF: O Serviço de Proteção e Atendimento Integral à Família - PAIF, segundo a Tipificação Nacional de Serviços Socioassistenciais. Brasília, DF, 2012.

CARVAlHO, M. C. B. de. Assistência Social: reflexões sobre a política e sua regulação. Revista Serviço Social \& Sociedade, São Paulo, v. 27, n. 87 especial, p. 123-131, set. 2006.

COLIN, D. Apresentação. In: Brasil. Ministério do Desenvolvimento Social e Combate à Fome. Orientações Técnicas sobre o PAIF: O Serviço de Proteção e Atendimento Integral à Família - PAIF, segundo a Tipificação Nacional de Serviços Socioassistenciais. Brasília, DF, 2012. p. 5-6.

CONSELHO FEDERAL DE SERVIÇO SOCIAL (Org.). A Atuação do Assistente Social no CRAS. Cadernos, v. 4. São Paulo: Publicação do CRESS-SP 9a Região, 2009. (Sistematização de dados do levantamento realizado pela Comissão de Orientação e Fiscalização COFI-CRESS-SP 2009).

IAMAMOTO, M. V. Serviço Social em Tempo de Capital Fetiche. 5. ed. São Paulo: Cortez, 2011.

LOPES, M. H. C. O tempo do SUAS. Revista Serviço Social \& Sociedade, São Paulo, v. 27, n. 87 especial, p. 7695, set. 2006.

PAIVA, B. A. de. O SUAS e os direitos socioassistenciais: a universalização da seguridade social em debate. Revista Serviço Social \& Sociedade, São Paulo, v. 27, n. 87 especial, p. 5-24, set. 2006 .

PEREIRA, M. C. M. Caridade versus Filantropia: Sentimentos e Ideologia. 2004. Disponível em: $<$ http://ler.letras. up.pt/uploads/ficheiros/5016.pdf>. Acesso em: 20 dez. 2012. 
SANTOS NETO, A. B. dos. A constituição históricoontológica da ética e dos direitos humanos. Revista Katálysis, Florianópolis: Edufsc, v.14, n. 2, p. 172-181, jul./ dez. 2011.

SILVA E SILVA, M. O.;YAZBEK, M. C.; GIOVANNI, G. A Política Social Brasileira no século XXI: a prevalência dos programas de transferência de renda. 6. ed. São Paulo: Cortez, 2012.

SILVEIRA, J. I. Sistema Único de Assistência Social: institucionalidade e processos interventivos. Revista Serviço Social \& Sociedade, São Paulo, v. 30, n. 98, p. 335361, abr./jun. 2009.

SIMÕES, C. Curso de Direito do Serviço Social. 4. ed.São Paulo: Cortez, 2010.

SPOSATI, A. O primeiro ano do Sistema Único de Assistência Social. Revista Serviço Social \& Sociedade, São Paulo, v. 27, n. 87 especial, p. 96-122, set. 2006.

Recebido em 24 de maio de 2013

Aceito em 08 de outubro de 2013 